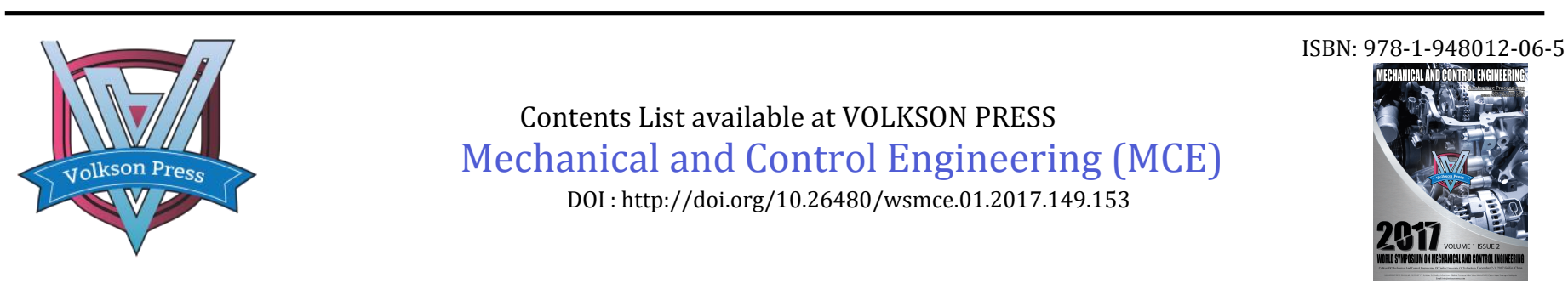

\title{
THE INFLUENCE OF HORIZONTAL RING RIB ON VIBRATION AND NOISE OF BOX GIRDER IN URBAN RAILWAY TRANSIT
}

\author{
Jiang Yu-Chun, Zhou Li, Zhang Tian-Qi, Luo Yan-Yun \\ Institute of RailTransit, Tongji University, No. 4800 Cao an Road, Shang Hai, Jiading District
*Corresponding Author: 283589771@qq.com
}

This is an open access article distributed under the Creative Commons Attribution License, which permits unrestricted use, distribution, and reproduction in any medium, provided the original work is properly cited

\section{ARTICLE DETAILS}

\section{Article History:}

Received 02 october 2017 Accepted 06 october 2017 Available online 11 november 2017

\section{Keywords}

box beam, horizontal ring ribs, vibration and radiated noise, finite element and infinite element

\section{ABSTRACT}

The box girder of urban rail transit is taken as the research object in this paper. By the combination of field measurement and numerical simulation, frequency spectrum of the vibration and radiated noise of the box girder during the train running is studied. It can be found that the main frequency bands of the box girder structure noise are in the range of $0 \sim 100 \mathrm{~Hz}$, and there is a certain correlation between vibration and noise. And the acoustic simulation method based on finite element and infinite element in ABAQUS can simulate the bridge structure noise well. On this basis, this paper further studies the vibration and radiated noise levels of the beams after the installation of horizontal ring ribs inside the box girder. By comparing the results, the horizontal ring ribs can reduce the vibration of bridge roof, floor as well as web and wing plate in some frequency band to a certain extent. Thus, it can reduce the noise sound pressure value in the corresponding frequency band, thereby reducing the overall structure noise of the bridge.

\section{INTRODUCTION}

With the increasing number of urban rail transit lines, the vibration and noise problems caused by the train during operation are paid more and more attention. Compared with the existing problems in the tunnel, the vibration and noise induced by the train on the viaduct affect the living of residents along the lines more significantly. Previous study shows that the sound level of urban rail transit on the viaduct during the operation could be up to over $90 \mathrm{~dB}$ on Line 5 of Beijing and Line 1of Shanghai, which exceeds the environment impact assessment and leads to a large number of complaints in the vicinity of the lines [1]. The existing mitigation measures controlling the bridge vibration are mainly based on some methods of the vibration isolation, and they can effectively reduce the vibration of the bridge. However, they also can increase the vibration and noise effect of the wheel-rail system, which will reduce its service life.

Considering of this, some projects tended to construct noise barriers on the viaduct. Apparently, they can reduce the wheel-rail noise considerably, but almost no effect on the structural noise of the bridge. By utilizing these mitigation measures of vibration and noise, the project has to be bigger and more expensive. In addition, the barrier installed on the viaduct can affect the landscape of the urban area greatly, which cannot be neglected. Therefore, it is necessary to seek a new approach to reduce both the vibration and the noise of lines on the bridge.

So far, there have been many studies on the vibration and noise problems of the elevated lines during operation. Based on the vehicle-bridge coupled vibration theory and sound wave propagation theory, Zhang He established the FEM-BEM hybrid simulation system of transient radiated noise induced from the bridge [2]. Zhang Xun studied the structural noise of box girder in the urban railway transit [3]. By utilizing the vehicle-trackbridge coupled vibration theory and boundary element method, an acoustic model of bridge structure was established in order to investigate the influences of material properties such as thickness, inclination angle and boundary conditions (simple support or consolidation) to the structural noise. Zhang Hui proposed a modified finite element method to analyze the dynamics of high speed train-track slab -bridge coupled system [4]. In his paper, the effect of vehicle speed, vehicle suspension parameters and track irregularity to the vibration displacement and acceleration response of the bridge were discussed. Zhai Wan-ming studied the dynamic response of the track and bridge structure, running safety, comfort and stability of the vehicles while the train running with high speed [5].

Among the researches about the structural noise simulation of viaduct in the urban rail transit, the finite element method is rarely used in the simulation. Meanwhile, considering that the structural noise of bridge is mainly concentrated in the range of low frequency, the grid density will not be very high, which can provide a new approach to the study of bridge structure noise. Therefore, this paper studies the bridge structure noise by using ABAQUS finite element software, with the combination of finite element and infinite element simulation.

\subsection{Study on Vibration and Noise Rules of Box Girder}

In order to obtain the vibration and noise response of the double-track box-girder of high-rise rail transit and to analyze the vibration and noise propagation law near the viaduct, this paper chooses a simple supported beam as the research object, and test the vibration and noise.

\subsection{Test Conditions}

The beam of the bridge is $2 \mathrm{~m}$ high and $9.6 \mathrm{~m}$ wide. The span of the bridge is $30 \mathrm{~m}$ and the height of the floor from the ground is about $9 \mathrm{~m}$. The simple beam is supported by double column piers. Considering the vibration response of the simply supported beam bridge is maximal in the mid-span, this paper selects the cross-section of the bridge as the test section. In the vibration larger parts of bridge roof, floor, web and wing, that is the midpoint of each plate, the acceleration sensor is arranged respectively, and the sensor is perpendicular to the board. Vibration and noise field test photos are shown in Figure 1. 


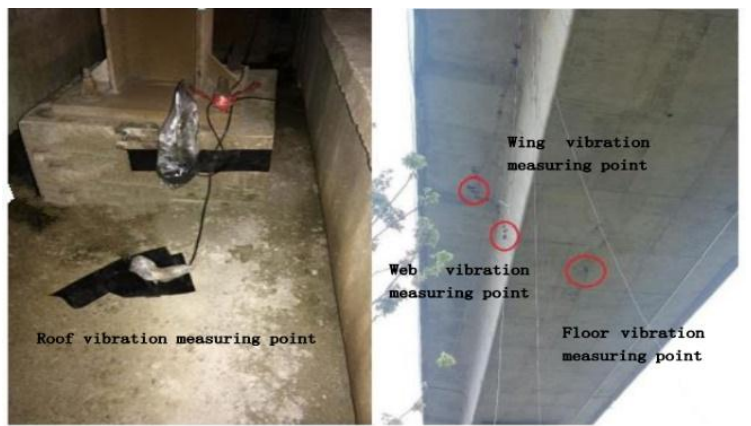

Figure 1: Site diagram of vibration test

1.3 Test Results Analysis
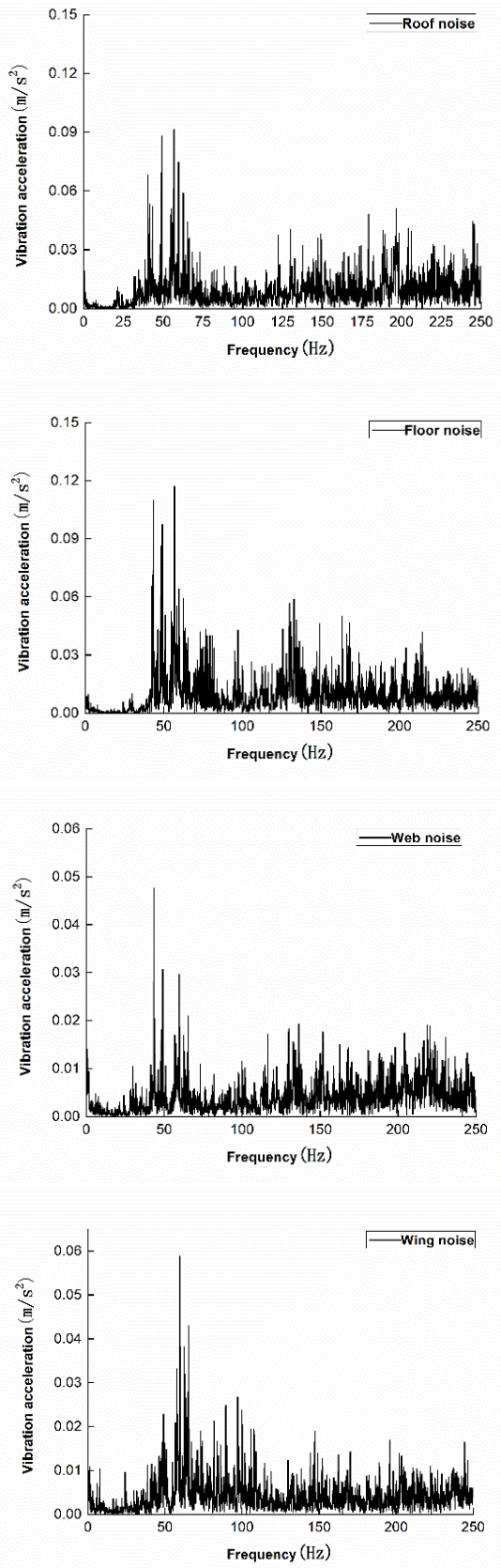

Figure 2: Vibration acceleration spectrum of box girder plates

From the analysis of measured vibration data, it is available that: in the 0 $\sim 250 \mathrm{~Hz}$ band, the bridge vibration peak frequency of the plate in within $100 \mathrm{~Hz}$. Among them, the vibration peak frequencies of the roof and the floor are $35 \mathrm{~Hz} \sim 65 \mathrm{~Hz}$ and $45 \mathrm{~Hz} \sim 70 \mathrm{~Hz}$ respectively. The web vibration peaks are in the frequency range of $40 \mathrm{~Hz} \sim 70 \mathrm{~Hz}$, while the vibration acceleration of the wing reaches the peak in the frequency band of $45 \mathrm{~Hz} \sim$ $80 \mathrm{~Hz}$. In addition, the plates have small local peaks in the frequency range of $100 \mathrm{~Hz} \sim 250 \mathrm{~Hz}$. From the view of peak acceleration in frequency domain, the vibration acceleration peak of floor is the largest, followed by the roof, and the acceleration of web and wing are smallest.

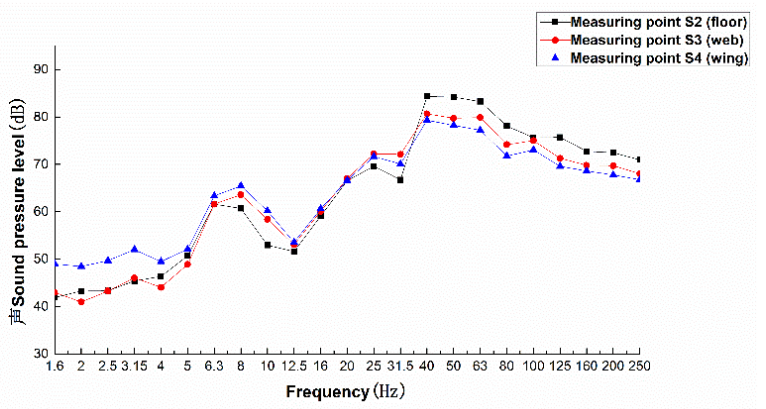

Figure 3: Near-field noise spectrum of the plates

According to the measured noise data, the main frequency bands of the structure noise at the measuring points S2, S3 and S4 are all within the range of $40 \mathrm{~Hz}$ to $80 \mathrm{~Hz}$. After crossing the main frequency band, the sound pressure level gradually decreases. From the whole frequency band $(1.6 \mathrm{~Hz} \sim 250 \mathrm{~Hz})$, the sound pressure level in the frequency band of $40 \mathrm{~Hz} \sim 250 \mathrm{~Hz}$ are greater than that of $1.6 \mathrm{~Hz} \sim 31.5 \mathrm{~Hz}$. That is, the plate near-field noise energy is mainly distributed in $31.5 \mathrm{~Hz} \sim 250 \mathrm{~Hz}$. And within the main frequency range, the near field sound pressure level of each band of the same plate has a little difference. Generally speaking the noise of bridge structure shows obvious low-frequency characteristics. The change trend of the near-field noise spectrum characteristics of each plate (bottom plate, web and wing) is basically the same, and the noise energy mainly concentrates in the main frequency range.

In the range of $1.6 \mathrm{~Hz} \sim 250 \mathrm{~Hz}$, there is a nonlinear relationship between the vibration acceleration of plate and the corresponding sound pressure level of radiated noise. In the low-frequency section, the sound pressure level of structure noise also increases with the increase of vibration acceleration of each plate. While the frequency exceeds a certain value, the sound pressure level of structural noise decreases with the increase of the plate vibration acceleration.

\section{VIBRATION AND STRUCTURAL NOISE SIMULATION ANALYSIS OF BOX GIRDER}

\subsection{Vibration Simulation and Analysis of Box Girder}

In this paper, the structural dynamic response of the straight-line bridge under vehicle load and the structural noise of outward radiation are studied. Since the vibration in the other two directions is far less than the vertical vibration, this paper mainly considers the dynamic factors related to vertical vibration. At the same time, this paper also studied the nod, shaking his head, floating, rolling, traversing, 5 degrees of freedom in total, of the body, bogies and wheel pairs. The physical unit is used to define the rail and bridge model. The face-to-face contact is used to define the wheelrail contact. Finally, the simulation model of vehicle-rail-bridge dynamics, which uses the system as a stimulus, is shown in Figure 4.

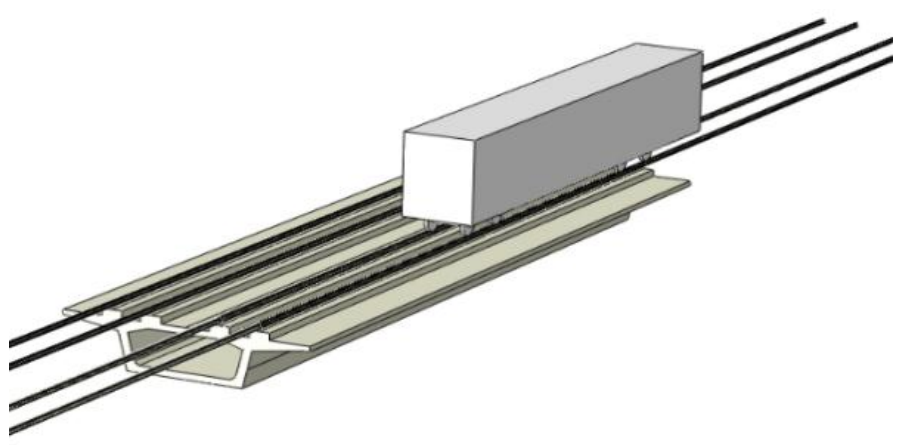

Figure 4: Vehicle-track-bridge dynamic simulation model

Modal analysis can be used to understand the mode shape and natural frequency of the box girder, and then the response of bridge when these modes are excited under dynamic loads is studied. 

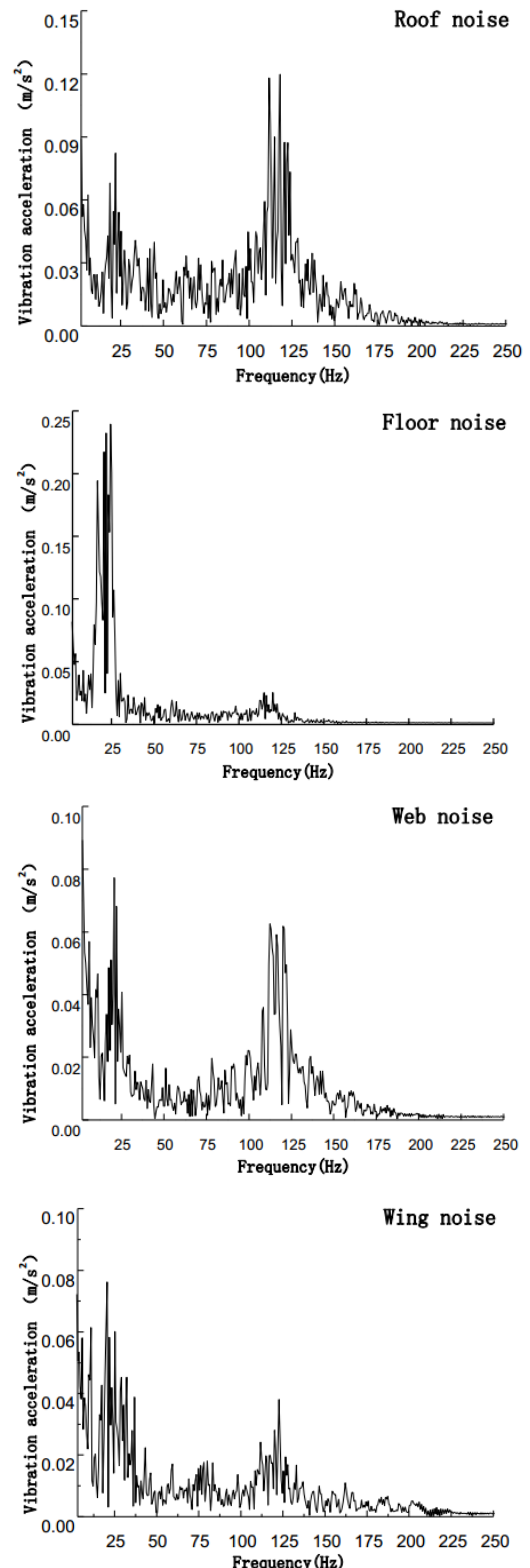

Figure 5: Simulation results of mid-point vibration acceleration

Comparing Figure 4 and Figure 5, it is found that the simulation results are not much different from the measured results from the view of vibration peak value. The vibration distribution characteristic of each plate is basically consistent with the measured results. Most of the main frequency bands are within $100 \mathrm{~Hz}$, and it matches the relationship of vibration intensity among the plates. Therefore, it can be considered that the simulation model can reflect the dynamic response characteristics of the bridge plates under the vehicle load to some extent.

\subsection{Noise simulation and analysis of box beam}

The method of ABAQUS continuum coupling Analysis is used in this paper. A model is re-established in ABAQUS / Standard, and structural noise sound field is simulated in it. The boundary conditions between the bridge structure and fluid interface and the sound field external boundary are set. In the sound field, the maximum global size is set as $0.2 \mathrm{~m}$, and the interface between sound field and solid is set as the acoustic-solid coupling interface unit.

Comparing the mid-point near field noise simulation result of each plate, it is found that the simulation results of the near-field noise radiated by the bridges are basically the same in the main frequency range and have obvious low-frequency characteristics. After the main frequency band, the noise sound pressure level gradually decreases as the frequency increasing. Near-field noise spectral characteristics of the floor and the wing change trend are basically the same as well as the amplitude of each frequency, which is consistent to the measured results.

Therefore, although the near-field noise of main frequency range and the amplitude of different frequency band in the simulation results are not completely consistent with that of the measured results, the simulation results can fully reflect the change tendency of the near-field noise as well as the main frequency spectrum characteristics and the relationship among the near-field noise of all plates, which illustrates the reliability of the model.

\section{INFLUENCE ANALYSIS OF HORIZONTAL RIBS ON VIBRATION AND NOISE OF BOX GIRDERS}

\subsection{Influence Analysis of Horizontal Ribs on Vibration of Box Girders}

The addition of horizontal ribs inside the box girder can increase the rigidity of the bridge and improve the local stiffness of roof, floor and web, thereby reducing the vibration response of the bridge. In the finite element model, horizontal ring ribs are added inside the box girder. The width of the rib is $0.3 \mathrm{~m}$, and the thickness is $0.2 \mathrm{~m}$. Take middle section of $30 \mathrm{~m}$ bridge as a symmetrical plane, and the ribs evenly arranged on both sides with $2 \mathrm{~m}$ distance between the two ribs. There is a total of 14 horizontal ring ribs inside the box girder. And the material property of ribs is the same as concrete beam.
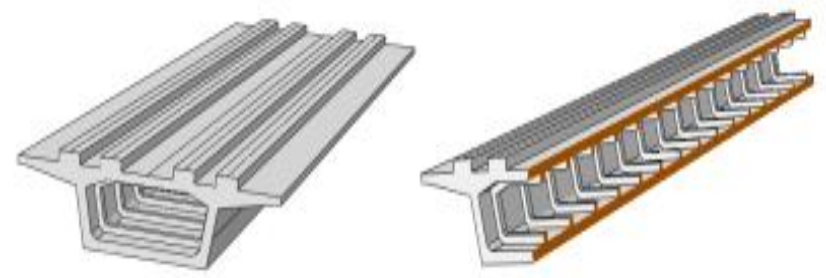

Figure 6: Box beam diagram with horizontal ring ribs

By comparison, it can be found that adding horizontal ribs can increase the modal frequency of the box girder, and the modal changes obviously. At the same time, due to the addition of horizontal ribs, the box girder flexural capacity increases, so the box beam is more for the longitudinal torsion in the first few modalities.
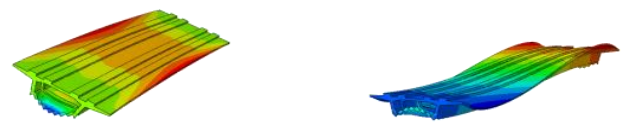

First-order modal frequency: $8.6 \mathrm{~Hz}$

Second-order modal frequency: $17.8 \mathrm{~Hz}$
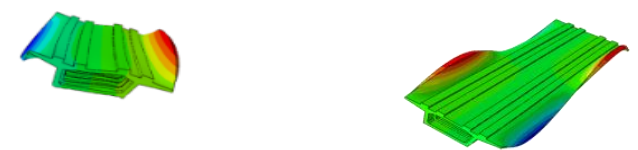

Third-order modal frequency: $25.2 \mathrm{~Hz} \quad$ Fourth-order modal frequency: $33.6 \mathrm{~Hz}$
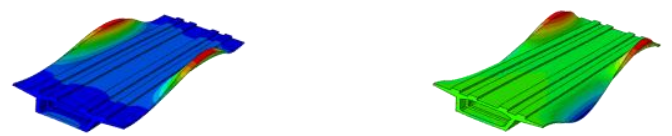

Fifth-order modal frequency: $34.2 \mathrm{~Hz} \quad$ Sixth-order modal frequency: $35.6 \mathrm{~Hz}$

Figure 7: Vertical mode diagram of ordinary box girder with horizontal ring ribs

\subsection{Simulation of Box Girder Vibration Response and Analysis of} Vibration Reduction Effect

After finite element simulation, the time-history data of the mid-point vibration acceleration of the ribbed box girder under vehicle load can be obtained. The Fourier transform of the time-domain data is used to get frequency-domain results that are compared to the dynamic response of each plate without structural optimization measures (ordinary box girder).

As shown in Figure 8, compared to ordinary box girder, adding horizontal ring ribs inside the box girder cannot effectively reduce the vibration of the bridge roof. In the frequency band corresponding to the two vibration peaks of common box girder roof $(15 \mathrm{~Hz} \sim 40 \mathrm{~Hz}$ and $100 \mathrm{~Hz} \sim 40 \mathrm{~Hz})$, the vibration of the roof with horizontal ring ribs increases at some 
frequencies instead.
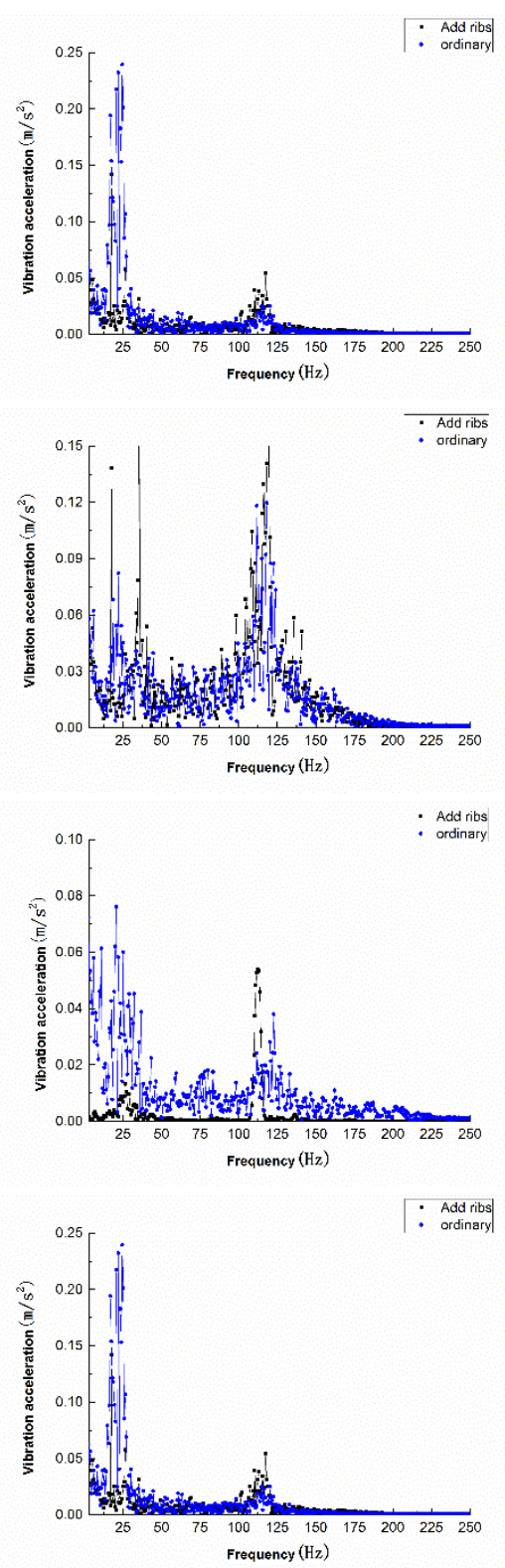

Figure 8: Spectrum comparison of vertical vibration acceleration of each plate

After the installation of horizontal ring rib, the vibration of the bridge floor are effectively suppressed, especially the vibration main frequency band $(15 \mathrm{~Hz} \sim 30 \mathrm{~Hz})$ of the ordinary box girder floor plate. At the frequency range of $110 \mathrm{~Hz} \sim 125 \mathrm{~Hz}$, the addition of horizontal ring rib makes the floor vibration increasing instead. The horizontal and vertical vibrations of the webs are not improved in the box girder with horizontal ring ribs, even in some frequency band, vibration amplification phenomenon is appeared.

'Especially, vertical vibration of the rest frequency except main frequency band, in addition to vibration of the frequency vibration is almost amplified. The vibration of other frequency bands except for the frequency range of $110 \mathrm{~Hz} \sim 115 \mathrm{~Hz}$ is reduced after the addition of horizontal ring ribs. It is very obvious that the addition of horizontal ribs can improve the vibration level of the wing. In general, the vibration acceleration amplitudes of the bridge floor and the wing plate are obviously reduced after the lateral ring ribs, especially in the main frequency band $(15 \mathrm{~Hz} \sim 40 \mathrm{~Hz})$ of the structure noise. But vertical vibration damping effect of the roof and the web is less than ideal. In some frequency bands, vibration of the plate is suppressed. But at some frequencies, the vibration increases instead, which may cause the near-field noise of top plate and web plate to be amplified near the frequency.

\subsection{Influence Analysis of Horizontal Ribs on Noise of Box Girders}

Figure 9 shows the structure noise sound pressure cloud chart of the ribbed box girder when the vehicle runs to the middle section of the bridge. It can be seen from the figure that there is obvious noise "hot spot" near the bridge roof, floor, web and wing next to the side of the line where the vehicle runs.

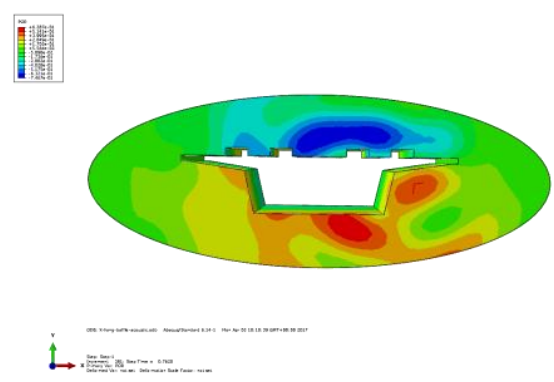

Figure 9: Structure noise pressure cloud chart of ribbed box

As can be seen from Figure 10, the sound pressure level in the original noise main band $(16 \mathrm{~Hz} \sim 31.5 \mathrm{~Hz})$ is reduced, especially at the noise peak. Meanwhile, at the other two local peak bands $(5 \mathrm{~Hz} \sim 8 \mathrm{~Hz}$ and $100 \mathrm{~Hz} \sim$ $125 \mathrm{~Hz}$ ), the sound pressure level value is also reduced. However, the roof near-field structure noise of the ribbed box girder forms a new noise peak in the two frequency bands of $12.5 \mathrm{~Hz} \sim 20 \mathrm{~Hz}$ and $31.5 \mathrm{~Hz} \sim 40 \mathrm{~Hz}$, but the value of the noise sound pressure level increases, which is the reason of why the roof vibration increases in the corresponding frequency range.
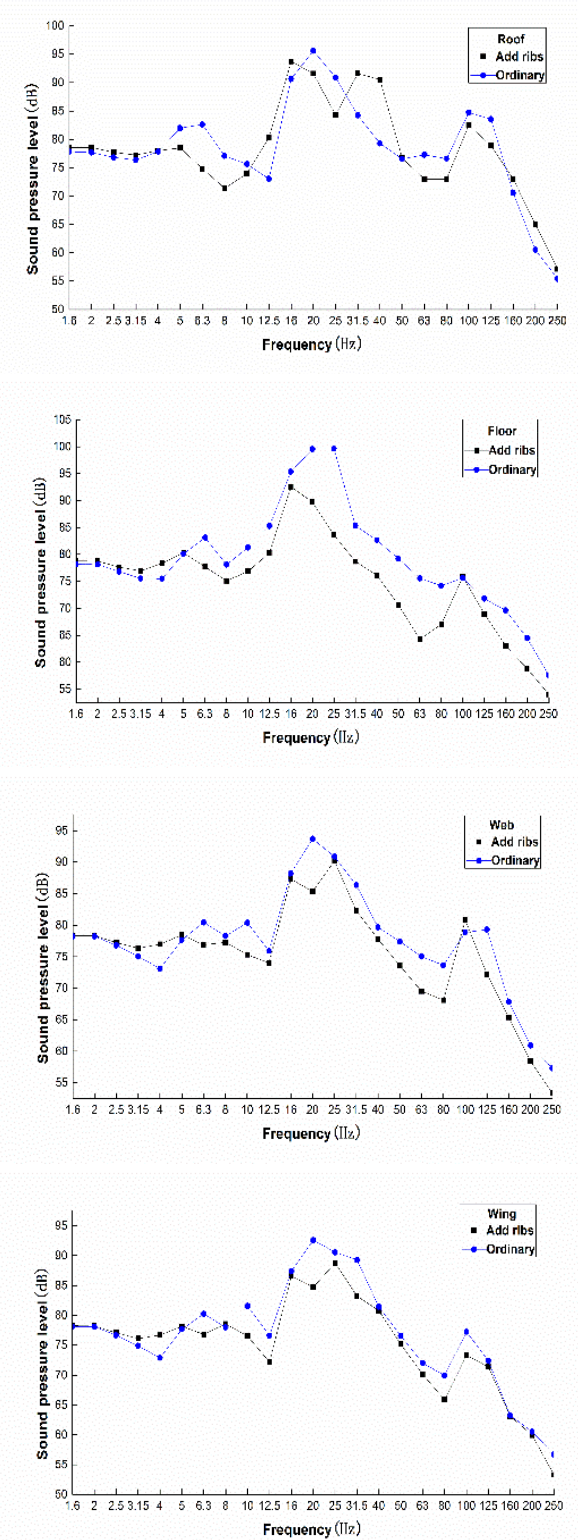

Figure 10: Comparison of near-field noise before and after ribbed

The near-field structure noise pressure of the common box girder floor is obviously suppressed in the main frequency band. This shows that the addition of horizontal ring ribs can significantly reduce the floor near-field 
structure noise. The sound pressure value of the band where the center frequency is $100 \mathrm{~Hz}$ is increased due to the increase of the vibration at the same frequency band. Except for $1.6 \mathrm{~Hz} \sim 5 \mathrm{~Hz}$, the sound pressure levels of the other central frequencies are all reduced.

Among them, the sound pressure reduction in the main band of original wing structure noise is the most obvious. In summary, the near-field structure noise of bridge floor, web and wing is significantly reduced. The total sound pressure level of near-field structure noise at floor is reduced by about $6 \mathrm{~dB}$. However, the near-site noise of bridge roof is slightly increasing. This is mainly due to the fact that the vibration acceleration corresponding to the main frequency band of the roof is increased after the ribbing.

Table 1: Table of near field noise sound pressure level before and after ribbed

\begin{tabular}{|l|l|l|l|l|}
\hline \multirow{2}{*}{} & \multicolumn{4}{|l|}{ Value of near field noise total sound pressure level (dB) } \\
\cline { 2 - 5 } & Roof & Floor & Web & Wing \\
\hline Ordinary box girder & 103.74 & 99.02 & 97.68 & 97.40 \\
\hline Ribbed box girder & 96.12 & 98.92 & 94.87 & 94.24 \\
\hline
\end{tabular}

Through table 1 and Figure 10, it is obvious that the addition of lateral ring ribs inside the box girder can effectively reduce the near-field structure sound pressure value of bottom plate and wing plate in each frequency band. In addition to the roof, the near-field structure noise pressure level of other plates in main frequency d can be significantly improved. In general, the addition of horizontal ring ribs inside the box girder can reduce the structural noise level of the bridge radiation.

\section{CONCLUSION}

Through the box girder field test of rail transit overhead line, the vibration and noise signals are processed and analyzed. The corresponding vehiclerail-bridge dynamic model and bridge structure noise model are established. The following conclusions are obtained.

(1) The study found that the main frequency bands of the roof, bottom, as well as web and wing plate near-field noise are below $100 \mathrm{~Hz}$. And the near-field noise sound pressure level of the bottom plate and the roof plate is larger than that of web plate and wing plate. The change trend of nearfield noise spectrum of each plate is basically the same.

(2) The comparison between the measured results and the simulation shows the accuracy of the acoustic model, which means that the combination of finite element and infinite element can solve the infinite acoustic field well.

(3) The horizontal ring ribs added inside the box girder at equal intervals improve the bending and torsion resistance of the bridge girder, so that the vertical vibration $(0 \sim 100 \mathrm{~Hz})$ of each plate under vehicle load can be controlled. And near-field structural noise pressure level of the floor and the wing in main frequency band is effectively reduced. In addition to top plate, the near-field structure noise of rest plate in main frequency has also been significantly improved, thereby reducing the bridge structural noise.

\section{ACKNOWLEDGEMENT}

The work was supported by the Natural Science Foundation of China (No. 51708422, No. 51678446)

\section{REFERENCES}

[1] Danqun, F., Bin, Z., Jiaqi, S., Weijian, L. 2013. Noise Control Engineering [M]. Beijing: Science Press, 156-157.

[2] He, Z., Xu, X., Yamashiro, Y. 2011. Analysis of Transient Noise of Vibration Radiation Caused by Traffic Load on Steel Box Girder Bridge [J]. Journal of Vibration Engineering, 24 (3), 221-227.

[3] Xun, Z., Xiaozhen, L., Quanmin, L., Jinfeng, W., Yadong, L. 2013. Constructional noise of concrete box girder and its influence factors [J]. Southwest traffic Journal of University, 48 (3), 409-414.

[4] Hui, Z. 2013. Dynamics Model of High Speed Train - Ballastless Track - Bridge Coupling System and Its Influence Parameter Analysis [D]. Lanzhou : Lanzhou University.

[5] Wan-ming, Z., Cheng-biao, C., Kai-yun, W. 2005. Dynamic Interaction Principle and Model of High-speed Train-orbit-bridge [J]. Chinese Journal of Civil Engineering, 38 (11), 132-137. 